\title{
(DES) CONSTRUAMOS AS CIDADES?: A RESISTÊNCIA DAS COMUNIDADES RIBEIRINHAS E PRAIANAS
}

\author{
Indira Angela Luza Eyzaguirre
}

Percorrendo milhões de quilômetros pelas trilhas aquáticas e terrestres do estado do Pará, motivada pelas questões socioambientais e a curiosidade de encontrar novos mundos com diferentes epistemes, chegue até uma comunidade ribeirinha localizada no rio Arumanduba numa das 72 ilhas do município de Abaetetuba, e uma comunidade praiana localizada em Quatipuru Mirim no município de Tracuateua. Eu, apenas uma observadora do mundo de episteme misturada (interiorana e citadina) num encontro com outros pensamentos evidenciados nas costumes do cotidiano da minha curta convivência nessas dois comunidades.

Essas comunidades que ainda resistem, independentemente da classificação como comunidades tradicionais segundo o sistema citadino, cidades que as construídas com recursos comuns definindo o privado do público no de acesso apenas para um grupo, como resultado da segregação baseada no capital econômico. Porém, as gênesis das crises humanas são na cidade, pelo fato de incentivar o individualismo além do nosso individualismo de mundos internos segundo Dumont, diferente da filosofia baseada no coletivismo das comunidades ribeirinhas ou praianas. A imigração ocorre frequentemente pelo direito ao crescimento evidenciado nas estadísticas do progresso econômico, mas não em pro do desenvolvimento coletivo praticado nestas comunidades, inclusive com seus próprios conflitos, para não cair no pensamento das sociedades e natureza selvagem estudado por Diegues. Com tudo, as comunidades que ficam fora do mercado, ou seja, na zona vulnerável segundo os padrões citadinos tem uma resistência ante o sistema pela prática da sua tradição junto com suas costumes e seu conhecimento local, tudo evidenciado nas relações políticas que definem a cultura com a ausência ou presencia de conflitos socioambientais.

1 Engenheira Ambiental e estudante de mestrado do programa de Pós graduação em Biologia Ambiental, Universidade Federal do Pará, e-mail de contato: indiraluza@gmail.com 
Portanto, se questiona se a construção das cidades devem seguir o modelo de infraestrutura atual?, um modelo que formata as diversas culturas e pensamentos como estas comunidades. Infraestruturas citadinas baseadas no discurso universal de desenvolvimento, sustentado pelos recursos "periféricos" e muitas vezes silenciando no planejamento territorial e ecológico as representações da população emudecendo o conceito de cultura que depende do contexto espaço-temporal, ou segundo Nandy (2015), cultura como linguagem da resistência, como necessidade histórico ante a opressão por causas "nobres" de crescimento cientifico e tecnológico. A construção das cidades em território latino-americano não legitima as relações de humanos e não-humanos numa realidade tradicional, porém o foco dessas cidades somos nós, híbridos modernos, caracterizados pela individualidade observada na infraestrutura de nossa sociedade "clinkercêntrica" baseada no cimento, o cimento como recurso principal de toda cidade moderna, criticado pelo mesmo conceito de modernidade sujeita as pressões da competitividade num mundo de ganhadores e perdedores, mencionado por Latour (2013) numa dupla tarefa de compreender até o pós-moderno, a dominação e a emancipação. Portanto, a resistência do mundo do sul suportada pela infraestrutura da revolução e os usos de recursos locais como a madeira, recurso que se adapta a toda uma diversidade que define as relações sócio culturais, onde emerge uma filosofia anti "clinkercêntrica" que questiona o progresso como tal:

El desarrollo llegó al mundo del sur como una analogía de dos procesos: la ciencia moderna asociada al evolucionismo y la teoría del progreso, y el colonialismo moderno, buscando legitimidad en una nueva misión civilizadora. El desarrollo heredó de la ciencia la creencia de aumentar el poder de la humanidad sobre el cosmos no humano (QUIJANO 2014).

Com tudo, se evidencia a resistência dos povos ribeirinhos e praianos mediante as costumes e suas infraestruturas misturadas com as estruturas naturais, se adaptando a geomorfologia da natureza de GAIA; diferente da filosofia "clinkercêntrica" pela construção de estradas e a edificação de prédios quadrados e frios em busca do progresso do individualismo. Essas comunidades emergem no vasto território da floresta amazónica, já seja perto do mangue ou perto do rio onde pessoas ficam nas moradias de vanguarda tradicional. Assim, se percorre pelos caminhos aquáticos do rio Arumanduba, uma comunidade ribeirinha, lá em Abaetetuba onde se observo muitas particularidades nessas duas semanas 
de janeiro de 2016. Viajando pelas águas desse rio se percebeu as relações humanas fundamentadas num concepto "hidro-geocéntrico" pela relação com a terra pelo roçado e o rio como principal ator destas dinâmicas; assim as casas de madeira da mesma terra nos campos da ilha são levantadas na vera do rio, junto aos navios oferecendo uma visão de diversas cores que contrasta com o verde da floresta e o marrom das casas e do rio. Esses laços fraternais com a terra se vem nas escrituras indígenas nos navios, traduzido ao português como língua citadina oficial. Assim, se levanta essa comunidade ribeirinha de população misturada entre índio, caboclo, quilombola e o pessoal de fora, quem ficam admirados pelos formatos das casas, direcionadas ao rio que guarda a episteme da comunidade; essas casas de diversas cores com janelas que ficam abertas para o vento entrar no interior e trazer com ele às partículas de tradição. Frente às casas fica o rio Arumanduba, que é o provedor de alimento ribeirinho pelo peixe, arraia e camarão oferecido, e por trás caminhando uns quantos metros fica o outro sustento: à roça e as árvores de terra firme como o açaí, que é apanhado, coletado e batido pelos mesmos comunitários para o almoço e a janta, dois vezes por dia os 365 dias do ano. A conexão do rio com a terra, e da terra com a roça estão plasmadas também nas trilhas de madeira unidas entre as casas, por onde se percorre de um calor familiar ao outro; essas trilhas por onde caminham os mais velhos, os adultos, os jovens e onde é o lugar das brincadeiras das crianças, claro como toda dinâmica social estas trilhas conectam o humano e não-humano, a diferença das estradas de cimento baseado no clinker na cidade de Abaete. O significado de trabalho para estas comunidades é completamente outro, um trabalho para o sustento dentro do cotidiano com vista ao rio, esse rio por onde passam navios, pessoas, mentes e representações observadas desde o interior de uma casa no interior da cidade, através da janela de madeira que conecta a sala de reunião onde os visitantes chegam e pelo outro lado a floresta da outra ilha conectada pelo mesmo rio. Por tanto, esta viagem imagética termina no dia com o pôs do sol e com o regresso a casa, desde à vera de uma ilha numa comunidade ribeirinha, pelo popopô até o pneu do ônibus que é suportada pela infraestrutura citadina.

Do mesmo modo, como esses caminhos aquáticos ribeirinhos guiam até comunidades de terra firme, outros caminhos mais ao nordeste do Pará, uma semana de junho de 2016 me encaminharam pelo rio Quatipuru até a sua comunidade praiana. Esta comunidade guarda nas suas estruturas de madeira pensamentos conectados a esse não-humano: o mar; que se conecta com os pensamentos individuais dos coletivos familiares através das trilhas de areia que dão uma bem vinda às pessoas que vem de fora no 
popopô, depois da viagem no ônibus desde o município de Tracuateua. Assim, se chega até a vera desta comunidade praiana de casas de madeira do mangue ou de te terra firme, mas sempre conectando as estruturas naturais de GAIA com as infraestruturas dessa mesma natureza. Todo numa simples e natural adaptação ante à erosão eólica e hídrica, numa resiliencia junto com a resistência deste povo ante a imigração pelo progresso que oferece as metrópoles junto com o trabalho remunerado que modifica as dinâmicas desta comunidade. Mas, com tudo isso os comunitários mais velhos (em sua maioria pescadores artesanais) preferem apenas ir a esta metrópole apenas pelo acesso a alguns bens como a água e voltar para suas casas de madeira, com janelas sempre abertas para o vento do mar entrar e ver essa enigmática paisagem depois do laborioso intercambio mercantil citadina. De tal modo, esses espaços de areia suportam as dinâmicas de pesca artesanal na vera e de alto mar, até os instrumentos e ferramentas que os pescadores usam são da própria GAIA, como os paus para os currais, é claro as dinâmicas mercantis citadinas dão aceso a materiais como as redes que eles usam no seu cotidiano, pescando guiados pelo seu conhecimento astronômico mediante as estrelas, astros e constelações. Assim como as casas, estão os ranchos que fazem contraste com a paisagem do lugar, na vera a praia invadida pela areia e acima os ranchos, infraestruturas construídas das estruturas arbóreas e a poucos metros os campos onde ficam outros ranchos, que servem como armazém do carvão elaborado nas caeras construídas pelas próprias mulheres. Tudo converge nos laços culturais arraigados à terra de areia evidenciado nas festas e festivais, onde emergem diversos pensamentos individuais como parte do conhecimento local coletivo. Também essa areia que suporta à comunidade praiana de Quatipuru Mirim é lugar das brincadeiras coletivas transmitidas culturalmente pelas gerações anteriores; olhando às crianças olhar no alto vasto do firmamento no ir e vir do papel das pipas, na brincadeira de soltar os papagaios. Por tanto, esta narrativa imagética termina com esta viagem visual dentro de uma alteridade no olhar desde o interior de uma casa de madeira no interior de uma comunidade praiana, finalmente só fica aguardar a noite deixar invadir o céu junto com todas suas estrelas e ver o pessoal da comunidade na vera das suas casas contando piadas ou conversando do seu cotidiano, só coisas relevantes.

Depois de conhecer as diferentes culturas de resistência das comunidades no interior do Pará, se pode questionar os modelos citadinos baseado em infraestruturas de cimento legitimados pelo planejamento territorial que define e até certo ponto impõe modos de viver formatando assim pensamentos, representações, identidades e assim a própria cultura. Porém, se deve avaliar se é preciso construir mais 
metrópoles ou no caso, desconstruir essas políticas impositivas para transformar em políticas diferenciadas que incluam os povos e suas representações sobre seu território e espaço.

\section{REFERÊNCIAS}

NANDY, Ashis. A imaginação emancipatória. Desafios do século 21. Tradução de Joannes de Knegt. Brasil. Editora UFMG. 2015.

LATOUR, B. Jamais fomos modernos, ensaio de antropologia simétrica. Tradução de Carlos Irineu da Costa. Editora 34. Terceira edição. Brasil. 2013. 

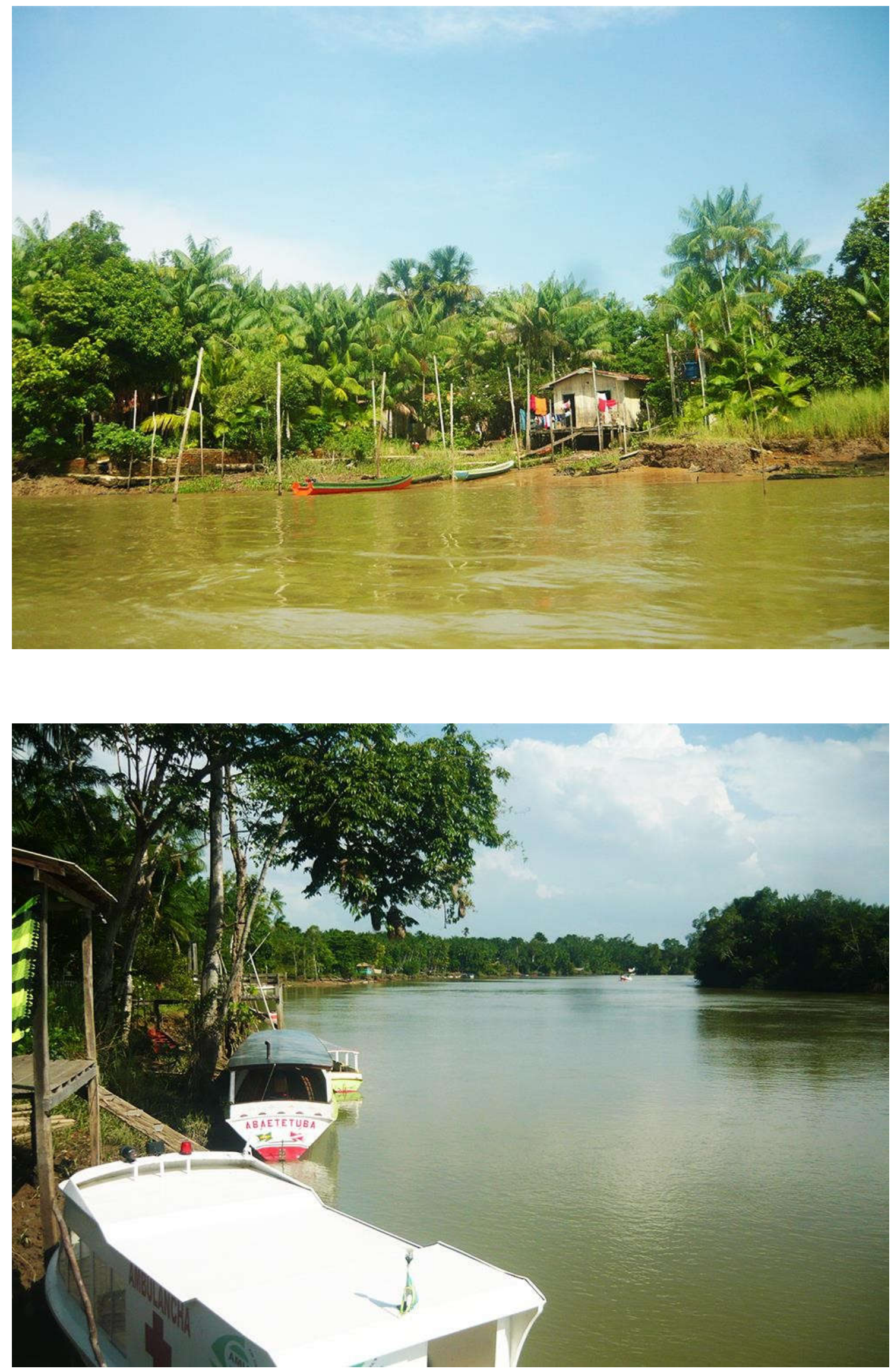

Nova Revista Amazônica - ANO IV - Volume 3 - DEZEMBRO 2016 - ISSN: 2318-1346 

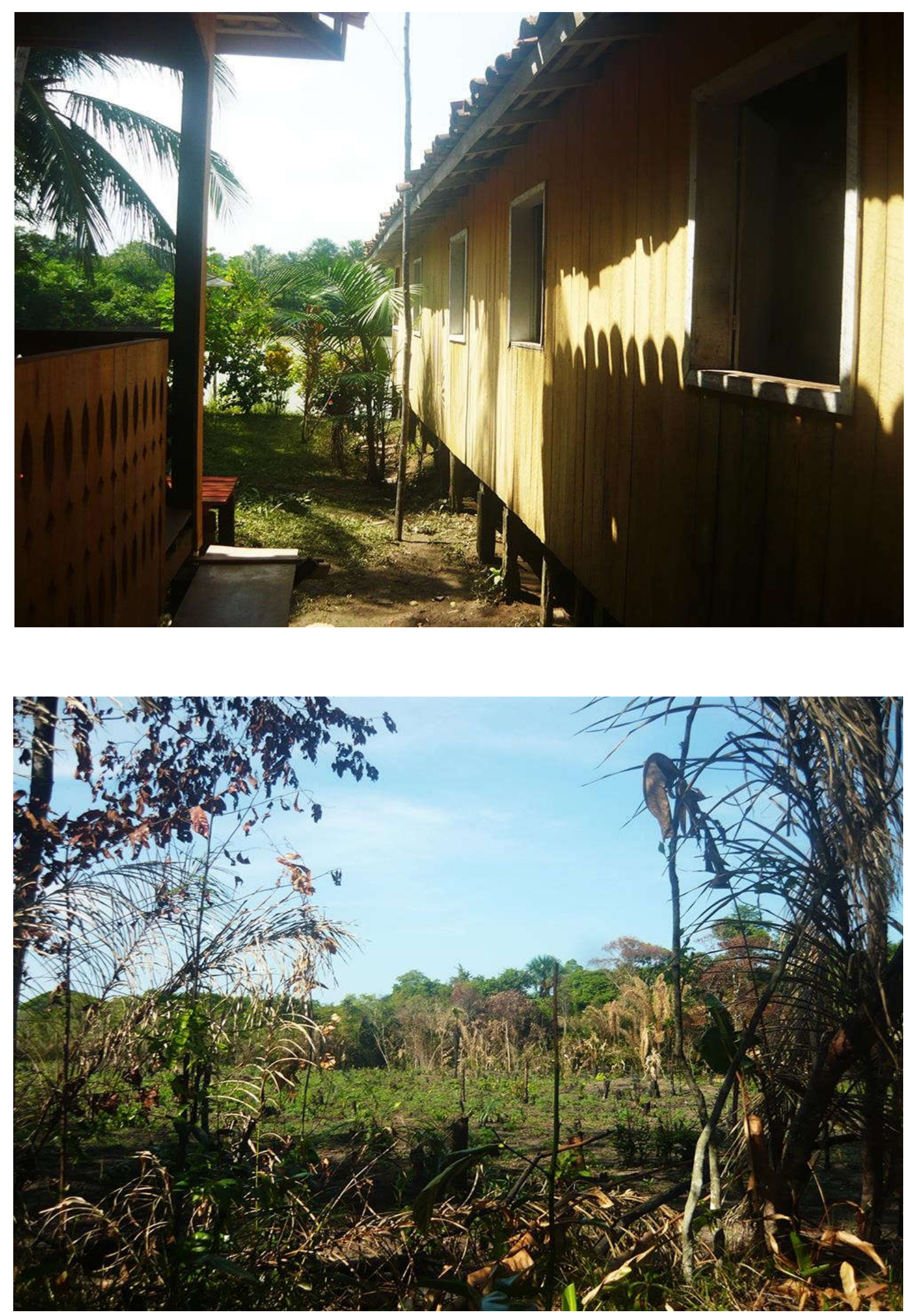

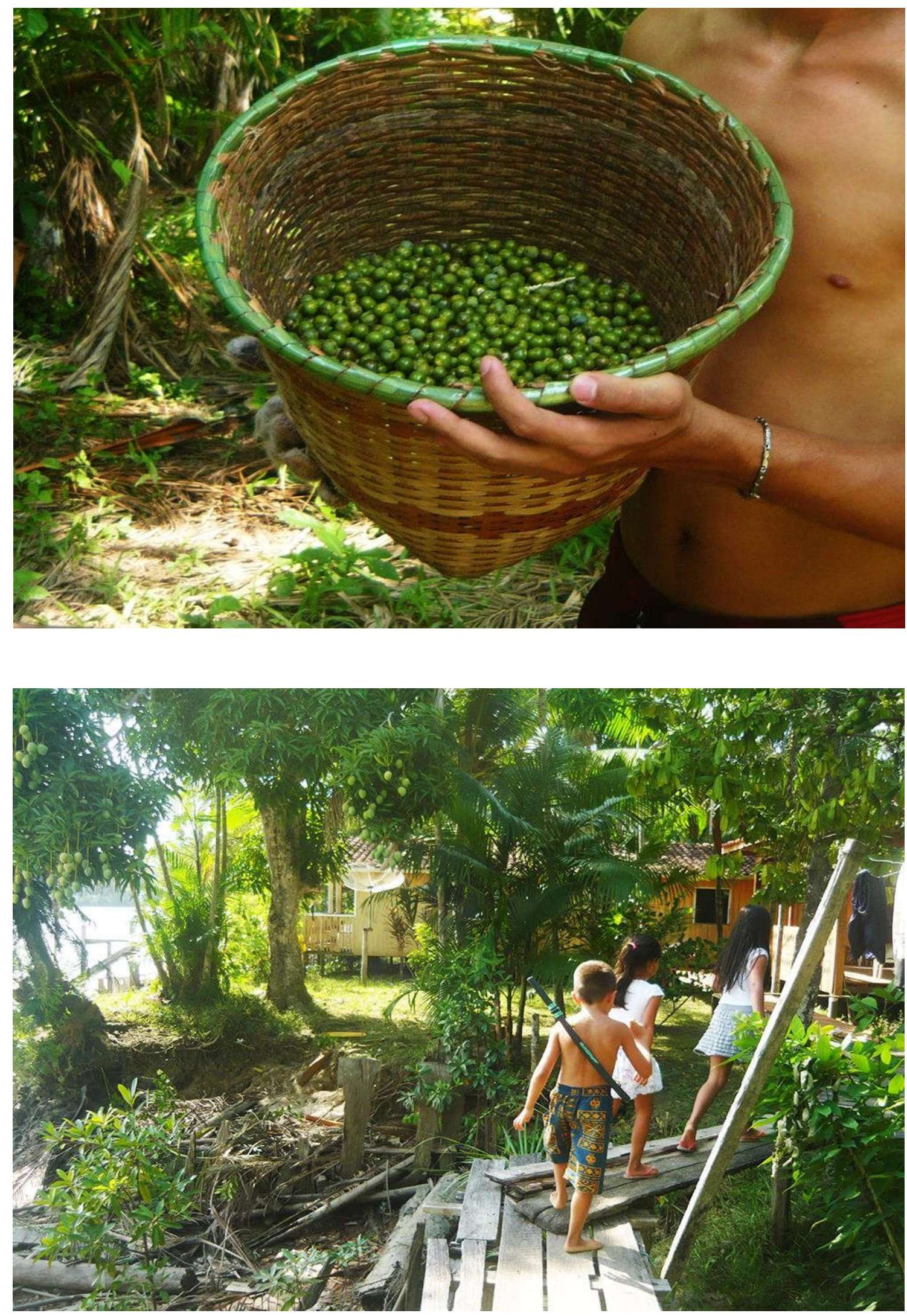

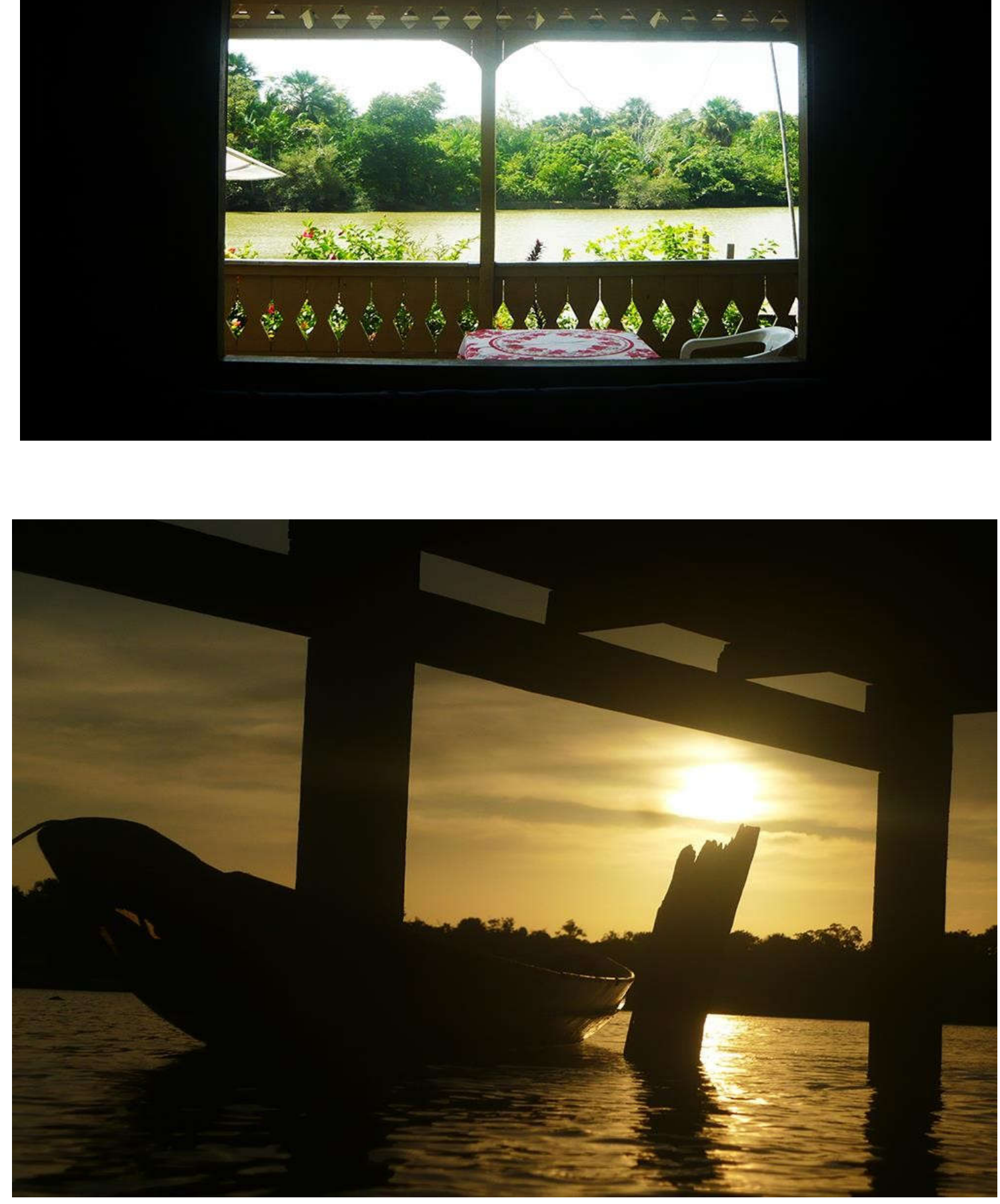

Nova Revista Amazônica - ANO IV - Volume 3 - DEZEMBRO 2016 - ISSN: 2318-1346 

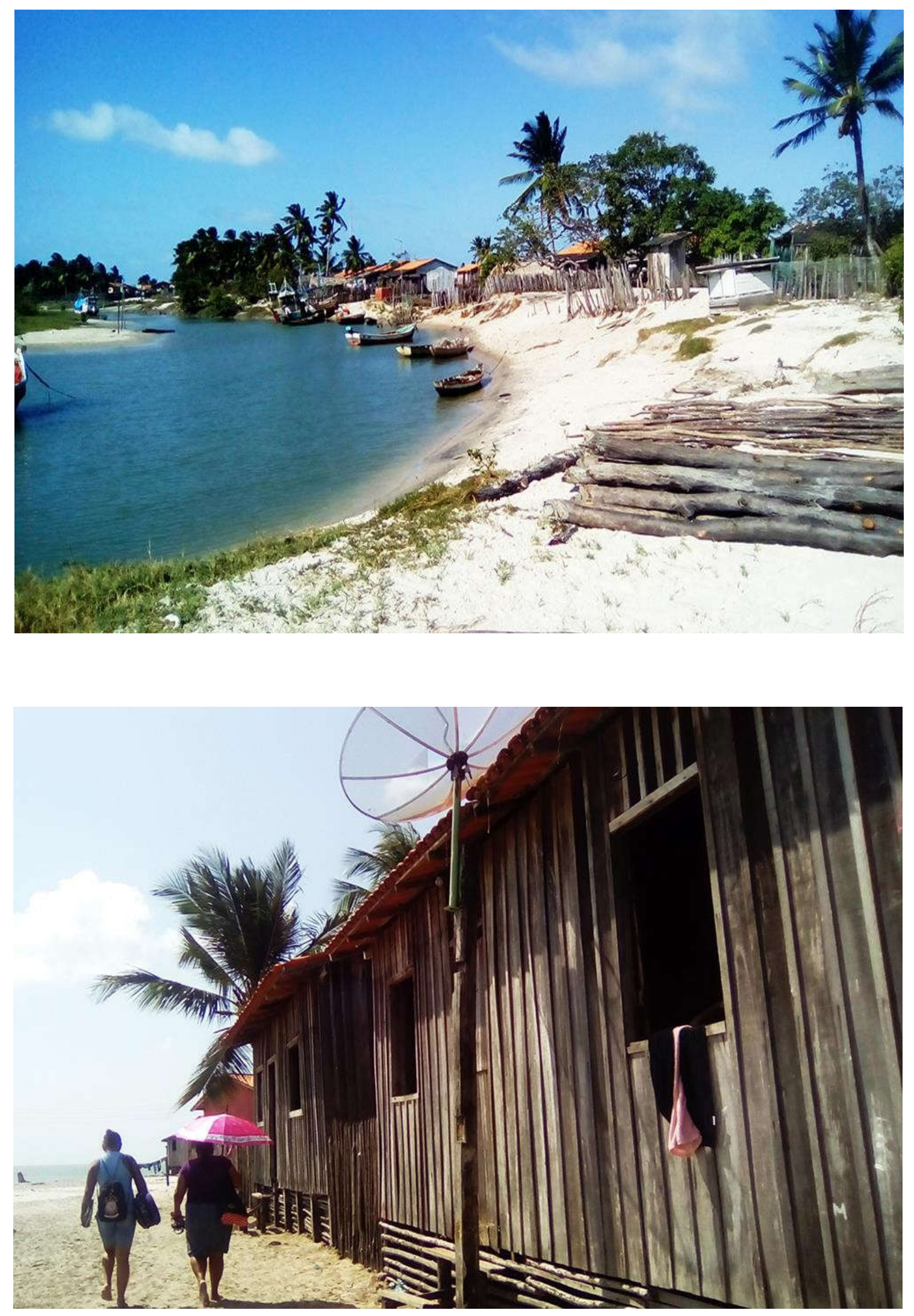

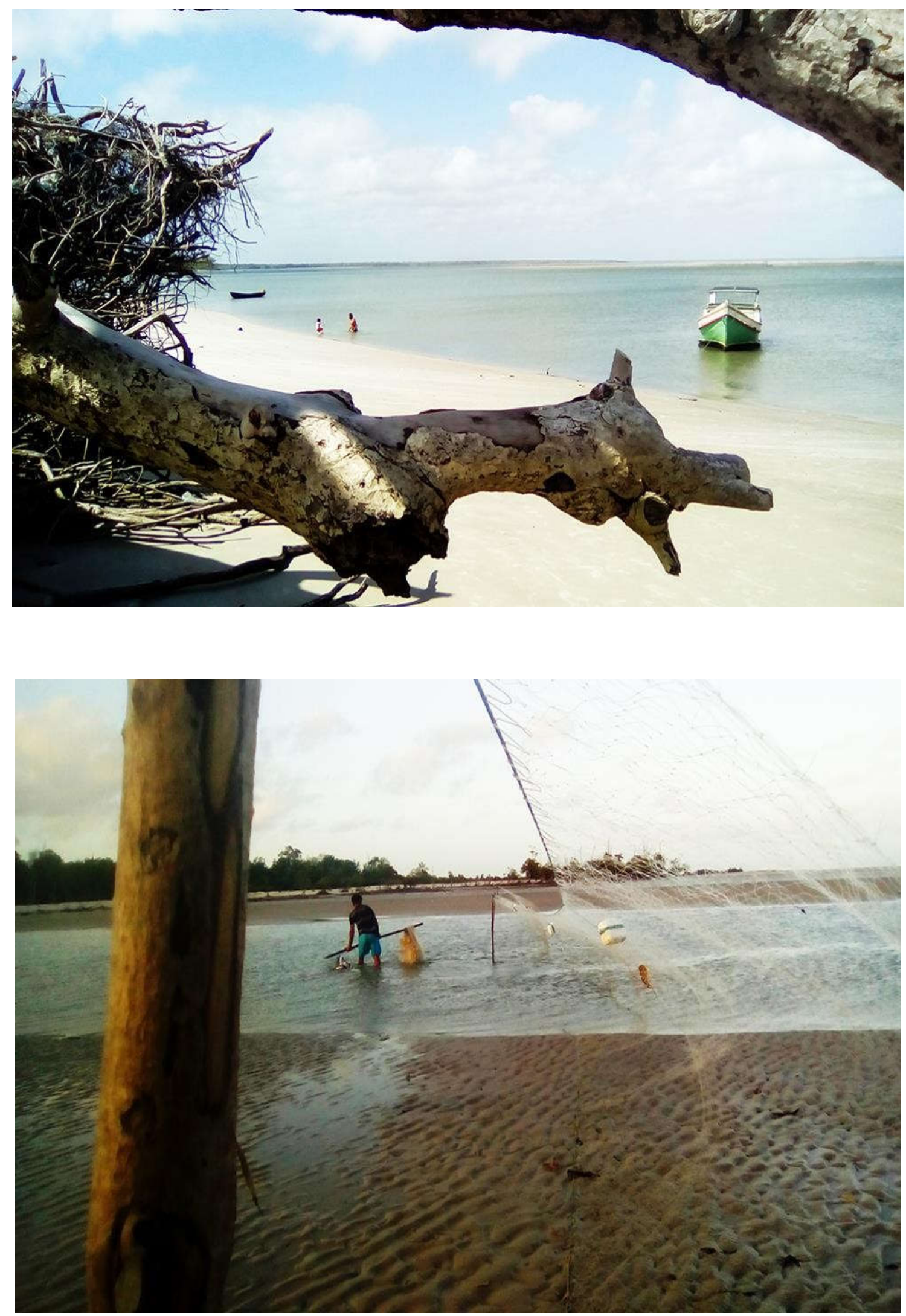

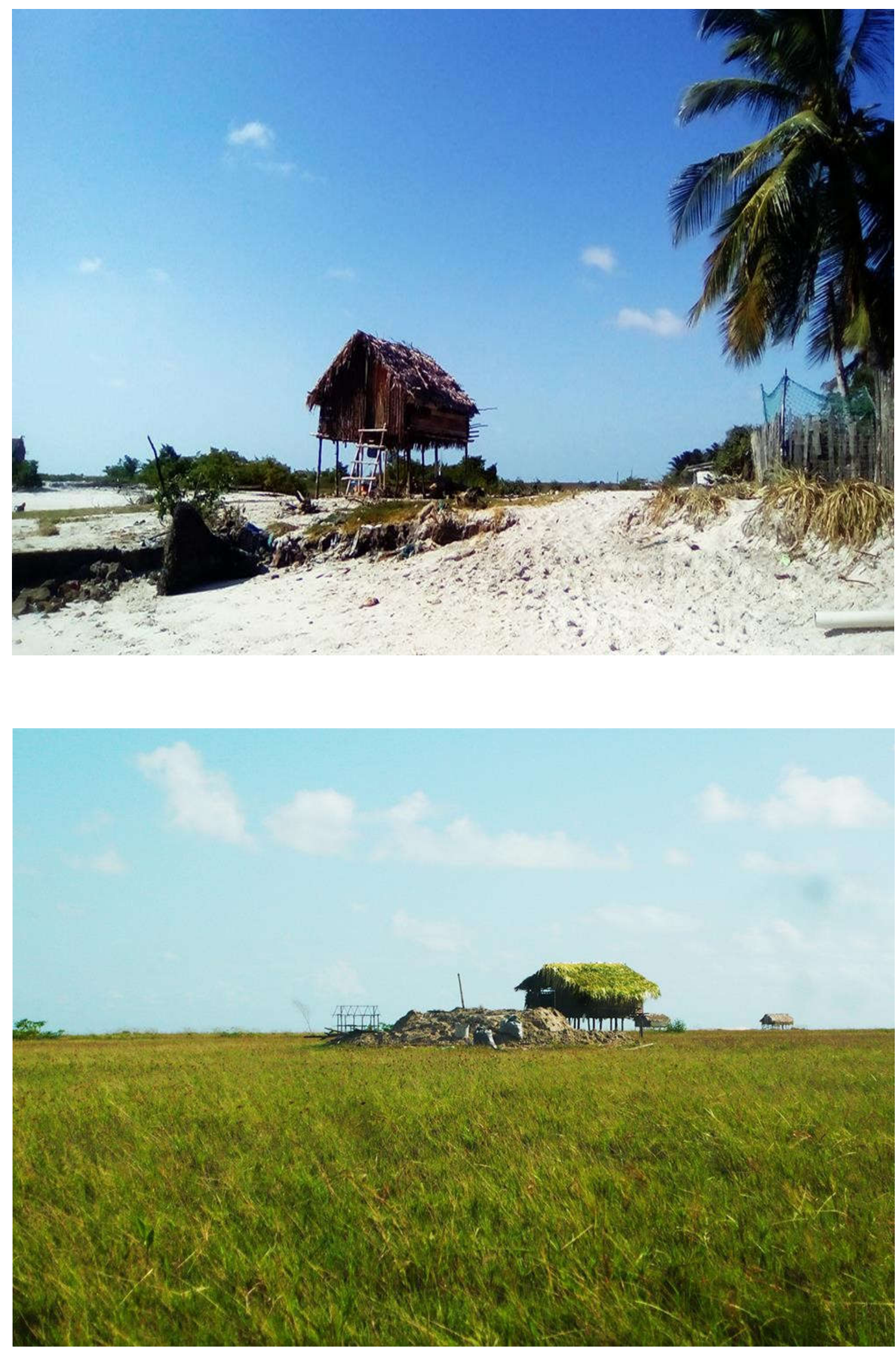

Nova Revista Amazônica - ANO IV - Volume 3 - DEZEMBRO 2016 - ISSN: 2318-1346 

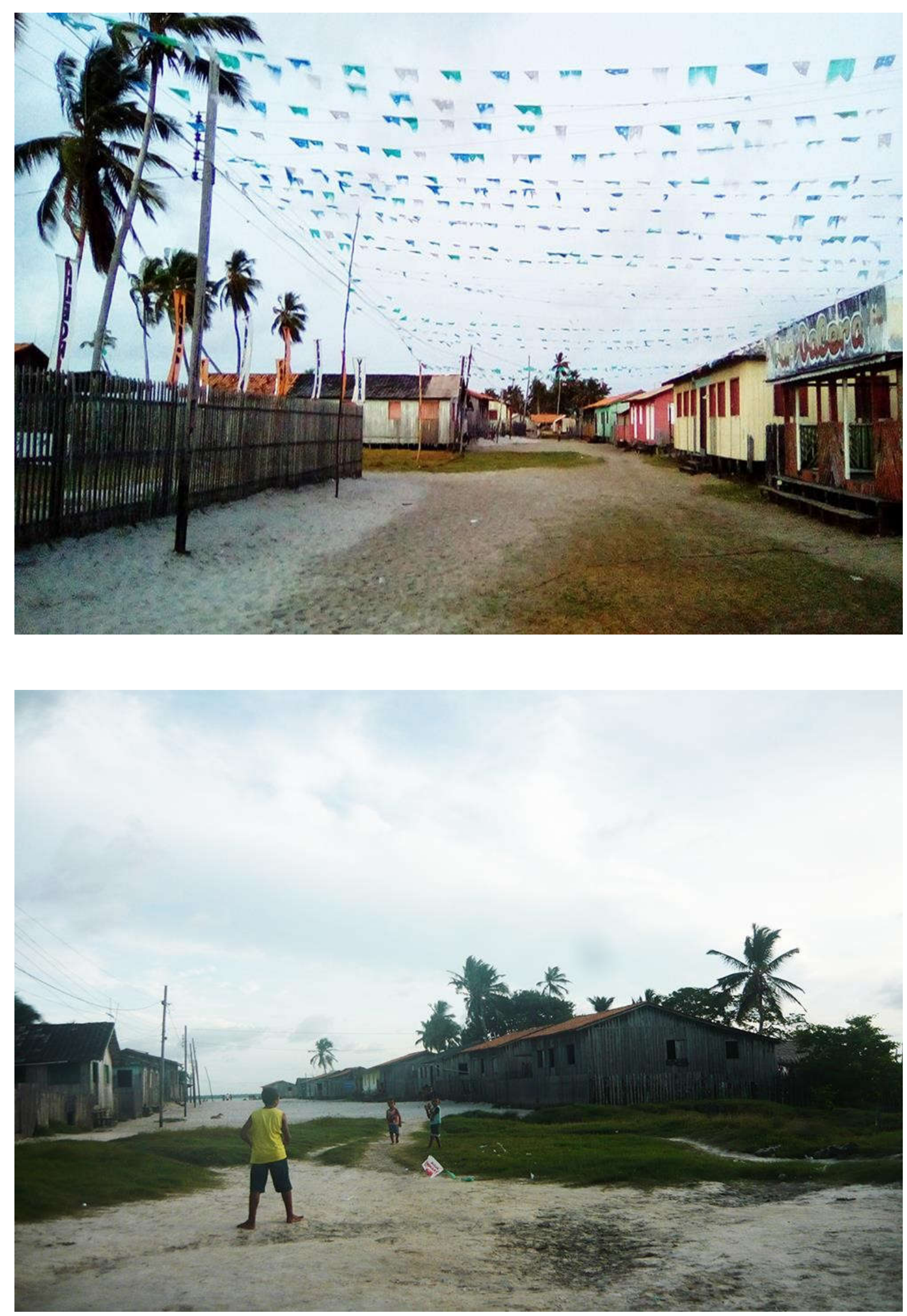

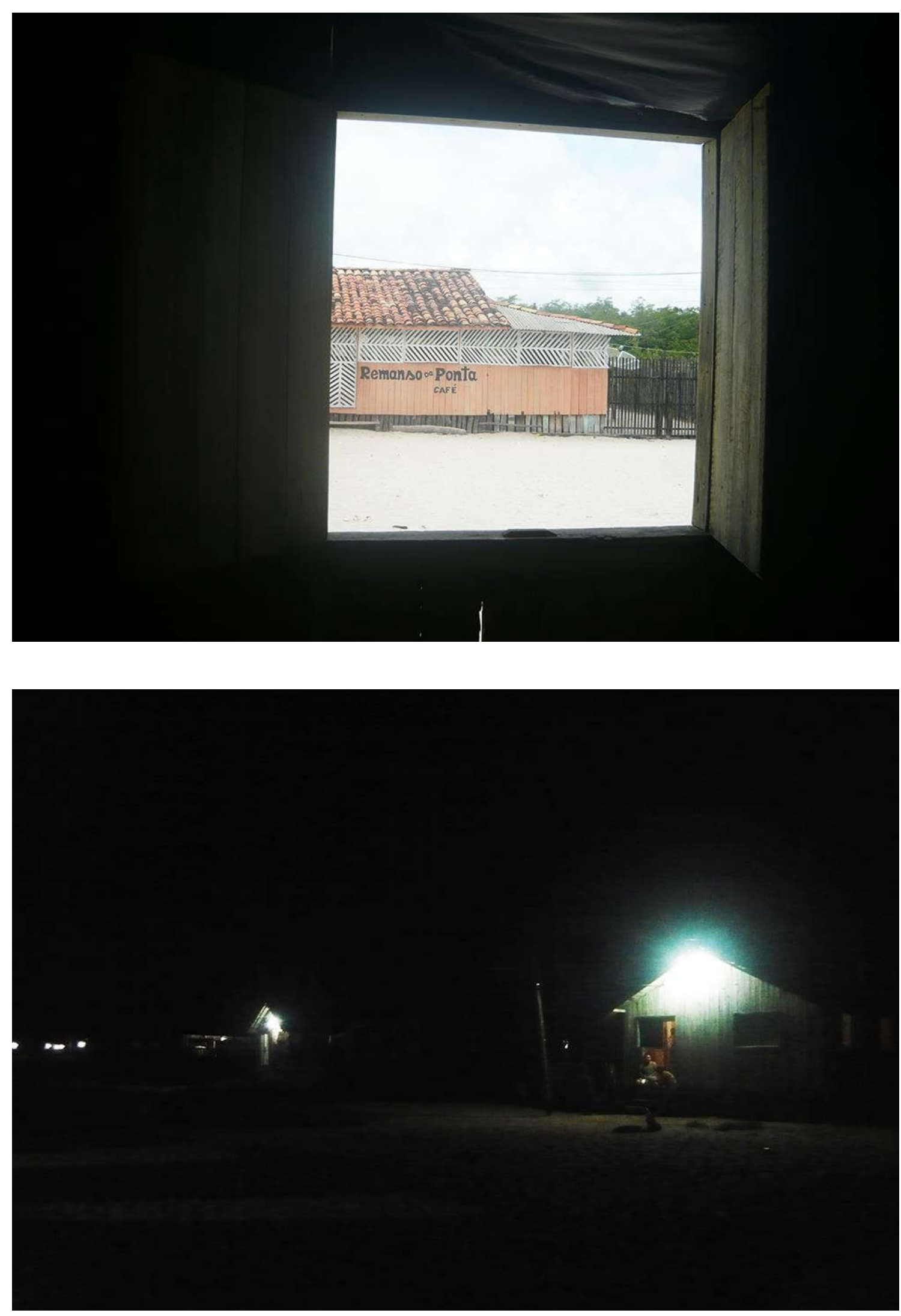

Nova Revista Amazônica - ANO IV - Volume 3 - DEZEMBRO 2016 - ISSN: 2318-1346 